\title{
The Role of Procedural Justice in Connecting the Contingent Punishments and
}

\section{Employees Responsiveness}

\author{
* Dr. Irfan Ullah Khan \\ ** Muhammad Saqib Khan \\ *** Hamid Khan
}

\begin{abstract}
In contemporary leadership theories, the proposition that leaders, who employ performance-based rewards and punishment are more effective than those leaders who use rewards and punishments just as incentives. Some researchers believe that punishments act as a motivational tool to promote responsiveness and improve performances of the employees while others assume that punishments produce undesirable consequences for the institutions. Similarly, the fairness in procedures in providing punishments to employees is the phenomenon of greater importance in connecting the contingent punishments and employees' responsiveness. Therefore, to examine these issues, in a native environment, data was collected through a structured questionnaire from employees working in higher educational institutions of Khyber Pakhtunkhwa, Pakistan. The results of the study, while applying the statistical procedures, provide valuable information for the eye-openers (employees, leadership, and management) of the institutions about the research issues under considerations. Together with, some recommendations, future directions, and practical implications have also been offered as emerged from the results of the study.
\end{abstract}

Keywords: Contingent Punishments, Procedural Justice, Employees Responsiveness \& HEIs Introduction

The workforces' responsiveness, in the higher educational context, has been considered as a significant predictor for various institutional outcomes likewise workforces' commitment, performance, and institutional credibility and success. The higher institutions need highly responsive and devoted employees to achieve high valued tasks and challenges of imparting quality education to upcoming prosperities (Ginkel \& Seddoh, 2002). In contemporary competitive situations, the responsiveness at workplaces brings along certain long-lasting effects on institutional standing and ranking. Thus, for workforces, to be responsive, persistent change in their attitude and behavior has become a massive challenge for institutions to meet desired standards and success (Diane \& Oliver, 2004). There are certain dynamic factors which are expected to improve employees' responsiveness like effective communication, balanced decision making and the willingness to respond, whereas some factors are responsible in declining employees' responsiveness likewise risk perception, tolerance for ambiguity and punitive behavior of leadership and management (Jayachandran \& Varadarajan, 2006).

To influence employees' behavior, the leader offers various rewards to inspire them towards the realization of an institutional vision. However, the leader also transacts certain punishments when desired objectives are not met within the required standards (Avolio, Walumbwa \& Weber, 2009). Rewards and punishments are used as incentives to inspire employees to show their efforts and potential towards the attainment of assigned tasks. The leader directs the employees to strictly follow the bee-line and required standards, however, any deviation might lead to unexpected punishments (Bass, Avolio, Jung \& Berson, 2012). For this purpose, the leader uses the coercive approach to grip the situation and to motive employees to respond to institutional objectives more efficiently. Conversely, punishments bring along certain undesirable effects on the attitude and behavior of the employees (Deng \& Leung, 2014). When leader practices coercive style (transactional), some resistance is eventually expected from employees which ultimately affect their responsiveness

\footnotetext{
* Department of Public Administration, Gomal University, Dera Ismail Khan, KP, Pakistan Email: drikmarwat@gmail.com

** Department of Business Administration, Gomal University, Dera Ismail Khan, KP, Pakistan

*** Gomal University, Dera Ismail Khan, KP, Pakistan
} 
towards institutional tasks. Here, the role of fair procedures is dynamic in punishing the employees who have their responsiveness to its minima.

Though, punishment produces undesirable consequences like retaliated behaviors, resentment, and increased anxiety which directly influences employees' responsiveness towards institutional tasks, however, fairness in procedures while providing punishments produces somehow positive effects in nurturing employees' behaviors (Muhammad, \& Shaheen, 2015). In this connection, the suitable task behaviors are contingent on positive reinforcement which increases employees' responsiveness while escape from institutional tasks and avoiding behavior are the outcome of negative reinforcement which results in minimum responsiveness and decreased performance (Elina \& Elita, 2017). Thus, fairness in procedures is vital for employees in providing suitable responses while it is vital for the institutions to chasing desired credibility and success. The fair procedures (acceptable \& accurate) and just decisions (unbiased \& consistent), based on ethical standards, are measured as dynamic tools in nurturing the employees' behavior (Ozsahin \& Yurur, 2019). Thus, procedural dimensions relate to standards that employees are equally treated as per fair institutional processes, norms, and values.

\section{Problem Statement}

The problem addressed in this study is related to the role of contingent punishments in affecting the employees' responsiveness. To what extent, the relationships between contingent punishments and employees' responsiveness is mediated by procedural justice in the main theme of the present study. This study aimed at exploring the said relationships (contingent punishments, procedural justice \& employees' responsiveness) in a higher education context in developing countries like Pakistan.

\section{Literature Review}

The employees' responsiveness is measured as a significant factor for organizations including higher institutions while managing the standards for success. The higher institutions, being the highest seats of teaching and learning, and being responsible for providing future leadership to different spheres, can achieve the desired objectives only when their employees are responsive towards institutional vision and mission (Martin, Trigwell, Prosser \& Ramsden, 2003). However, responsiveness might be influenced by many dynamic factors in which contingent punishments are the foremost (Avolio, Walumbwa \& Weber, 2009). The punishments, as provided to employees, due to deviation from standards, have diverse effects on employees' responsiveness and performances (Maryam, Suandi, Silong \& Omar, 2013). The contingent punishment harms employees' responsive behavior, however, this impression can be augmented to some extent due to the adaptability of fair procedures (Benson \& Martin, 2017). The employees' perception of procedural fairness while providing rewards and punishments is vital in shaping their behavior positively (Ozsahin \& Yurur, 2019).

\section{Contingent Punishments}

The rewards and punishments are attributes of transactional leaders which are dependent upon the performances at workplaces. The leader transacts rewards to those employees who meet the desired standards while punishing those who deviate from preferred standards (Judge \& Piccolo, 2004). This exchange relationship is considered by various researchers as inspirational tools for the employees towards decent performances (Avolio, Walumbwa \& Weber, 2009). The contingent punishments are related to economic and emotional exchanges due to the evaluation of the role requirements and outcomes/feedback (Odumeru, James \& Ogbonna, 2013). When tasks are assigned to employees along with the assurance of human and technical support, then it is the responsibility of employees to attain the tasks within required standards (Raimonda \& Modesta, 2016). Resultantly, the leader proposes the compliance standards and reproves those employees who are unable to meet standards. However, due to expected punishments, employees hesitate in acting and responding in their roles in achieving assigned tasks which eventually affects their responsiveness in institutions (Ford \& Stephens, 2018). 


\section{Employees Responsiveness}

For effective responsiveness, there is a need for a mature understanding and connection between employees and leadership in the institution. In organizational behavior, responsiveness is determined as a dynamic feature in defining the connection between institutional tasks, employees' efforts, and leader inspirations (Uphoff \& Moharir, 1994). The fairness in rewards, punishment, and procedures and effective responses are the main kinematics that directly affects institutional credibility and success (Jayachandran \& Varadarajan, 2006). Consequently, employees who are responsible and responsive, having compacted spirit and undaunted commitment, are expected to achieve assigned responsibilities wholeheartedly (Riaz \& Farooq, 2010). Likewise, the responsiveness is supportive in realizing the institutional goals and develop the output level of employees in institutions (Dutta \& Islam, 2017). In this connection, to promote responsiveness in institutions, leaders are required to psychologically empower the employees by concentrating on dynamic features like competence, understandings, meaning, and fairness perception which are vital in affecting responsiveness (Ford \& Stephens, 2018).

\section{Procedural Justice}

The effective mechanism for fair decision making about the policies, procedures, and processes is vital in shaping employees' perceptions and behavior. In this regard, contextual factors influence the employees' perception of fairness when receiving the unexpected decisions about undesirable outcomes (Cropanzano, Prehar \& Chen, 2002). Thus, institutional processes are vital in affecting responsiveness at workplaces as employees always expect fair and just procedures in decision-making (Cremer \& Blader, 2006). Similarly, the provision of punishments is considered a dynamic force in affecting the employees' responsiveness and institutional outcomes. In this drive, balanced decisions about fair procedures are vital in shaping the behavior and responsiveness of employees (Wang, Liao, Xia \& Chang, 2010). Resultantly, the fairness in procedures create just and positive linkages among different working units in the institution (Ko \& Hur, 2014). The punishment should be commensurate with efforts and responses that employees show in chasing institutional objectives (Matthew \& Stott, 2018). Thus, the fair procedure is expected to play a facilitating role in linking the punishments and responsiveness.

\section{Theoretical Framework}

In research, it is common saying that the researchers will have to stay away from the research topic in the sense that all research variables with their inter-relationships have to be extracted from existing literature thereby building a model (theoretical framework) from where the hypotheses have emerged. The theoretical framework of this study comprises predictor (contingent punishments), mediator (procedural justice), and criterion variables (employees' responsiveness). This framework shows the complete research process along with the development of research questions (hypotheses) $\left(\mathrm{H}_{1}\right.$ to $\left.\mathrm{H}_{2}\right)$. Figure 1 Theoretical Framework

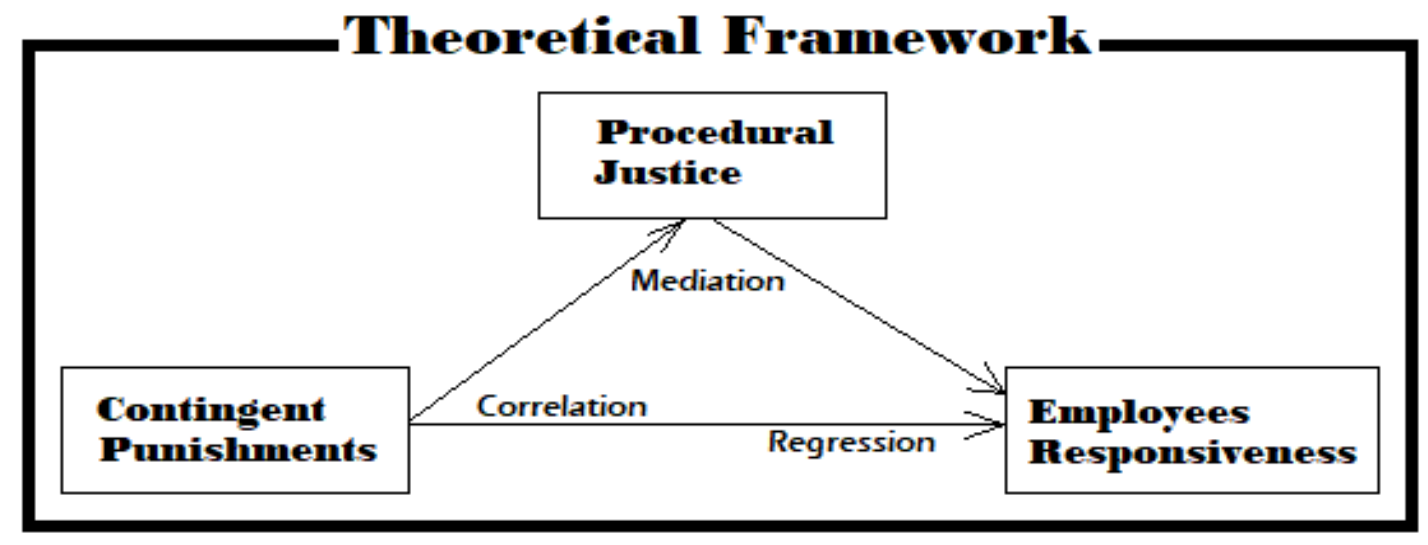

\section{Research Hypotheses}

$\mathrm{H}_{1}$ : The predictors (Contingent punishment \& Procedural justice) are positively and significantly associated with the criterion variable (Employee responsiveness).

$\mathrm{H}_{2}$ : The relationship between the predictor (Contingent punishments) and the criterion (Employees responsiveness) is significantly mediated by the mediator (Procedural justice). 


\section{Research Design}

The selection of appropriate research design is an important part of research after the topic selection and formulation (Ader, Mellenbergh \& Hand, 2008). The research design postulates the entire process likewise what type of data is necessary to collect, what type of methods are required to analyze the data, to answer the research questions (Creswell, 2014). The research design depends upon the nature of the study and acts as a bridge between the execution of the research strategy and finding the answers to research questions (hypotheses). Thus, the research design developed for this study comprises the descriptive as well as exploratory.

\section{Philosophy and Approach}

Positivism is the research philosophy adopted in this study as the study aimed at exploring existing realities by using an appropriate approach and applying the statistical procedure to answer research questions that emerged from the theoretical framework (Saunders, Lewis \& Thornhill, 2012). All these are requirements of the positivist approach, therefore, positivism is the research philosophy of this study. Moreover, based on the positivism approach, a survey approach is recommended as the best approach to access the population of the study.

\section{Population and Sample}

The population of the study comprises the employees from different administrative units of selected higher education institutions (target population). The hierarchical structure of institutions includes different working units (teaching \& non-teaching) which are considered as dynamic forces towards institutional credibility and success. The selected institutions include one university from the developed areas and one from underdeveloped areas of Khyber Pakhtunkhwa, Pakistan. From the population, the sample of 290 respondents was chosen by using the statistical formula of Yemeni (1986) thereby applying the random sampling technique.

\section{Data Collection and Analysis}

The secondary data was collected from the most relevant existing literature on the issues while the primary data was collected from a structured questionnaire to measure the research variables and their inter-relationships (association \& cause-\&-effect) among research concepts under considerations. The collected data was analyzed by using diverse statistical tools like correlation for association and regression for cause-\&-effect relationships. These tools thus helped the researcher in providing the information about the answers to the research questions (hypotheses) that emerged from the theoretical framework (Sekaran \& Bougie, 2011).

\section{Research Context and Measurement}

This study was conducted in the context of higher institutions due to their vital role in the developmental process of societies and countries. The research variables were measured over different items (questions) as asked from respondents (sample from a population). The questionnaire (instrument) was extracted from the previous research studies for the purpose to measure research variable in the native environment (higher education institution) likewise contingent punishments was measured through Chester, Tianothy, and Linda (1991), employees' responsiveness was measured through Uphoff and Moharir (1994) and distributive justice was measured over Greenberg (1990).

\section{Reliability Examination}

Table 1

Reliability Statistics

\begin{tabular}{llll}
\hline S.No & Variables & Items & Cronbach Alpha \\
\hline 1 & Contingent Punishments & 06 & .718 \\
2 & Procedural Justice & 06 & .831 \\
3 & Employees Responsiveness & 06 & .799 \\
\hline 4 & Questionnaire & 18 & .846 \\
\hline
\end{tabular}

The reliability statistics of variables in the instrument were examined through Cronbach Alpha wherein each variable was measure through six (6) items. The variables showed the good reliability in the examination since the computed Alpha values for each variable are above to acceptable/required value (.7) likewise the Alpha value for contingent punishments is (.718), procedural justice (.881) and 
employees' responsiveness (.799) while the overall computed value for the entire instrument is (.846). Therefore, the instrument has acceptable and good reliability as per the statistics.

\section{Validity Examination}

Table 2

Validity Examination (Contingent Punishments)

\begin{tabular}{lllll}
\hline KMO and Bartlett's Test & \multicolumn{3}{l}{ Matrix } \\
\hline \multicolumn{2}{l}{ A measure of Sample Adequacy (Kaiser-Meyer-Olkin) } & .742 & Items & Score \\
Bartlett's Test of Sphericity & Approximate Chi-Square & 392.236 & CP1 & .402 \\
& Difference \& Significance & $13(.000)$ & CP2 & .613 \\
& Required & & CP3 & .524 \\
Computed & KMO test & $=$ or $>.7$ & CP4 & .686 \\
.742 & Bartlett's test & $=$ or $<.05$ & CP5 & .478 \\
.000 & Factor Loadings & $=$ or $>.4$ & CP6 & .711 \\
Factor Loadings $=$ or $>.4$ & & & & \\
\hline
\end{tabular}

Table 3

Validity Examination (Procedural Justice)

\begin{tabular}{lllll}
\hline KMO and Bartlett's Test & \multicolumn{3}{l}{ Matrix } \\
\hline \multicolumn{2}{l}{ A measure of Sample Adequacy (Kaiser-Meyer-Olkin) } & .799 & Items & Score \\
Bartlett's Test of Sphericity & Approximate Chi-Square & 380.215 & PJ1 & .607 \\
& Difference \& Significance & $15(.000)$ & PJ2 & .422 \\
& Required & & PJ3 & .581 \\
Computed & KMO test & $=$ or $>.7$ & PJ4 & .534 \\
.799 & Bartlett's test & $=$ or $<.05$ & PJ5 & .636 \\
.000 & Factor Loadings & $=$ or $>.4$ & PJ6 & .408 \\
\hline
\end{tabular}

Table 4

Validity Examination (Employees Responsiveness)

\begin{tabular}{lllll}
\hline KMO and Bartlett's Test & & \multicolumn{3}{l}{ Matrix } \\
\hline \multicolumn{2}{l}{ A measure of Sampling Adequacy (Kaiser-Meyer-Olkin) } & .701 & Items & Score \\
Bartlett's Test of Sphericity & Approximate Chi-Square & 356.122 & ER1 & .721 \\
& Difference \& Significance & $14(.000)$ & ER2 & .564 \\
Computed & Required & & ER3 & .588 \\
.701 & KMO test & $=$ or $>.7$ & ER4 & .465 \\
.000 & Bartlett's test & $=$ or $<.05$ & ER5 & .615 \\
& Factor Loadings & $=$ or $>.4$ & ER6 & .584 \\
\hline
\end{tabular}

The above tables show the data fitness for structure detection over KMO and Barlett Tests which provides certain conditions for required and computed values. The sample adequacy is measured through the KMO test with the required value $(=$ or $>.7)$ while computed values for all research variables are above the required values $(.742, .799 \& .701)$ respectively which indicates that variables are best fitted for the factor analysis. Likewise, Barlett Tests provide information about the correlation matrix for structure detection with the required significance level $(=$ or $<.05)$. The results indicate that computed values for all variables are within the required range $(.000, .000 \& .000)$ separately. Similarly, for every value, commonality must be greater than extraction $(0.4 \%)$ which signifies the association between variables. The factor loadings values (computed) for all the items concerning all research variables are within the required range $(=$ or $>.4)$, thus, it shows the suitability of data for factor analysis.

\section{Data Analysis}

The results obtained through statistical procedures about relationships among research variables have been presented in the data analysis section. This section provides the answers to the research questions (hypotheses) as emerged from the theoretical framework. The descriptive and inferential tools have been used to examine the research variables' descriptions and interrelationships.

\section{Descriptive Results}

The descriptive research helps in offering valid and accurate descriptions/representations of research variables that were specified in the problem statement and theoretical framework of the study. It helps in providing the data about the sample-size, maximum and minimum response rate, mean, and the standard deviation. 
Table 5

Descriptive Statistics

\begin{tabular}{llllll}
\hline & $\mathrm{N}$ & Min & Max & Mean & Std. Deviation \\
\hline Contingent Punishments (IV) & 282 & 2.21 & 6.56 & 4.3515 & .55920 \\
Procedural Justice (MV) & 282 & 3.04 & 6.17 & 4.7941 & .65786 \\
Employees Responsiveness (DV) & 282 & 2.78 & 6.78 & 4.3653 & .66088 \\
\hline
\end{tabular}

\section{Testing of Hypotheses}

The explanatory research main theme is to recognize the relationships between research variables that are related to the research problem. In this connection, as specified in the problem statement, this study aimed at examining the relationships likewise the association (correlation) and cause-\&-effect (regression) among the research variables which were specified in the problem statement, theoretical framework, and research hypotheses.

$\mathrm{H}_{1}$ : The predictors (Contingent punishment \& Procedural justice) are positively and significantly

Table 6 associated with the criterion variable (Employee responsiveness).

Correlation Analysis

\begin{tabular}{llll}
\hline & & Procedural Justice & $\begin{array}{l}\text { Contingent } \\
\text { Punishment }\end{array}$ \\
\hline Contingent & Pearson Correlation & $.569^{* *}$ & 1 \\
Punishments & Sig. (2-tailed) & .000 & \\
Procedural & Pearson Correlation & 1 & $.569^{* *}$ \\
Justice & Sig. (2-tailed) & & .000 \\
Employees & Pearson Correlation & $.682^{* *}$ & $-.773^{* *}$ \\
Responsiveness & Sig. (2-tailed) & .000 & .000 \\
$* *$ Correlation is significant at the 0.01 level (2-tailed). &
\end{tabular}

The first hypothesis was about the association between predictors (Contingent punishment and Procedural justice) and a criterion variable (Employee responsiveness). The results from correlation provide significant information in deciding the connections among research variables likewise, employees' responsiveness is positively and significantly associated with procedural justice $(.682 \&$ $.000)$, however, significant but negative associated with contingent punishments (-.773 \& .000). Similarly, a positive and significant association was found between contingent punishments and interactional justice (.569 \& .000). Thus, negative association confirms that higher punishments, lower will be responsiveness, or lower the responsiveness, greater might be the punishments. Thus, from results, the first hypothesis is accepted.

$\mathrm{H}_{2}$ : The relationship between predictor (Contingent punishments) and the criterion (Employees responsiveness) is significantly mediated by the mediator (Procedural justice).

Table 7

Regression Analysis (Computing a)

\begin{tabular}{lllllll}
\hline \multicolumn{2}{l}{ Model Summary } & & & & \\
\hline Model & R & R Square & Adjusted R & SEE & F & Sig. \\
1 & $.596 \mathrm{a}$ & .669 & .662 & .36085 & 244.241 & $.000 \mathrm{~b}$ \\
\hline
\end{tabular}

Table 7a

Regression Analysis (Computing a)

\begin{tabular}{|c|c|c|c|c|c|}
\hline \multicolumn{6}{|l|}{ Coefficients of Regression } \\
\hline \multirow[t]{2}{*}{ Model } & \multicolumn{2}{|c|}{$\begin{array}{l}\text { Unstandardized } \\
\text { Coefficients }\end{array}$} & $\begin{array}{l}\text { Standardized } \\
\text { Coefficients }\end{array}$ & $\mathrm{t}$ & Sig. \\
\hline & B & Std. Error & Beta & & \\
\hline (Constant) & .878 & .275 & & 5.892 & .000 \\
\hline Contingent Punishments & .592 & .052 & .537 & 11.497 & .000 \\
\hline
\end{tabular}

a. Predictor: (Constant): Contingent Punishments

b. Dependent Variable: Procedural justice

The Barren and Kenny (1986) mediation model has been used in this study which is the execution of four steps procedures (paths a, b, c \& $\hat{c}$ ). The tables provide the information about the first path (a) regarding the impact of the predictor (contingent punishments) on the mediator (procedural justice). 
Results shows $67 \%$ variance in procedural justice is due to contingent punishments with significant impact (Beta-value $=.592 \&$ P-value $=.000$ ). Therefore, these results confirmed the condition that the first path (a) must be significant.

Table 8

Regression Analysis (Computing $c, \hat{c} \& b$ )

\begin{tabular}{|c|c|c|c|c|c|c|c|c|c|c|c|}
\hline \multicolumn{12}{|c|}{ Model Summary } \\
\hline \multirow[t]{2}{*}{ Model } & \multirow[t]{2}{*}{$\mathrm{R}$} & \multirow[t]{2}{*}{$\mathrm{R}^{2}$} & \multirow{2}{*}{$\begin{array}{l}\text { Adjuste } \\
\mathrm{d} \mathrm{R}^{2}\end{array}$} & \multirow[t]{2}{*}{ SEE } & \multicolumn{2}{|c|}{ Change Statistics } & \multirow[b]{2}{*}{ df1 } & \multirow[b]{2}{*}{ df2 } & \multirow[b]{2}{*}{$\begin{array}{l}\text { Sig. F } \\
\text { Chang } \\
\text { e }\end{array}$} & \multirow[b]{2}{*}{$\mathrm{F}$} & \multirow[b]{2}{*}{ Sig. } \\
\hline & & & & & $\begin{array}{l}\mathrm{R}^{2} \\
\text { Chang } \\
\mathrm{e}\end{array}$ & $\begin{array}{l}\text { F } \\
\text { Change }\end{array}$ & & & & & \\
\hline 1 & $-.772 \mathrm{a}$ & .443 & .400 & $\begin{array}{l}.5426 \\
8\end{array}$ & .289 & 166.354 & 1 & 289 & .000 & $\begin{array}{l}266.31 \\
7\end{array}$ & $\begin{array}{l}.000 \\
\mathrm{~b}\end{array}$ \\
\hline 2 & $-442 \mathrm{~b}$ & .788 & .785 & $\begin{array}{l}.2965 \\
4\end{array}$ & .377 & 354.278 & 1 & 377 & .000 & $\begin{array}{l}411.19 \\
8\end{array}$ & $\begin{array}{l}.000 \\
\mathrm{c}\end{array}$ \\
\hline
\end{tabular}

Table 8a

Regression Analysis (Computing c, $\hat{c} \& b$ )

\begin{tabular}{|c|c|c|c|c|c|c|}
\hline \multicolumn{7}{|c|}{ Coefficients of Regression } \\
\hline \multirow{2}{*}{\multicolumn{2}{|c|}{ Model }} & \multirow{2}{*}{\multicolumn{2}{|c|}{$\begin{array}{l}\text { Unstandardized } \\
\text { Coefficients }\end{array}$}} & Standardized & $\mathrm{t}$ & Sig. \\
\hline & & & & Coefficients & & \\
\hline \multirow{2}{*}{1} & (Constant) & 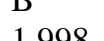 & 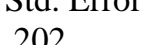 & & 8759 & 000 \\
\hline & Contingent Punishments & -.582 & .048 & -.520 & -11.284 & .000 \\
\hline \multirow[t]{3}{*}{2} & (Constant) & .869 & 192 & & 5.425 & .000 \\
\hline & Contingent Punishments & -.242 & .038 & -.138 & -4.578 & .000 \\
\hline & Procedural Justice & .562 & .068 & .662 & 18.214 & .000 \\
\hline
\end{tabular}

a. Predictors: Contingent Punishments d. Dependent Variable: Employees Responsiveness

c. Mediator: Procedural Justice

The table above provides the information about the second, third, and fourth paths of mediation (c, $\hat{\mathrm{c}}$ $\& b)$. The hierarchical regression provides two models of regression in deciding the mediation. In this connection, the first model shows the direct effect (c) about impact of predictor (contingent punishments) on the criterion variable (employees' responsiveness) thereby showing $44 \%$ variance in the employees' responsiveness due to the contingent punishments (Beta-value $=-.582 \&$ P-value $=$ .000 ). The second model shows the third and fourth paths of mediation by providing data about ( $\hat{\mathrm{c}})$ and (b). The second model shows 79\% variance in criterion (employees' responsiveness) is due to predictors (contingent punishments \& procedural justice). The path $(\hat{\mathrm{c}})$ show the significance of procedural justice in connecting the predictor and criterion variables (Beta-value $=-.242 \& \mathrm{P}$-value $=$ .000 ). The path (b) provide the impact of mediator on criterion variable (Beta-value $=.562 \&$ P-value $=.000)$. The results show that procedural justice partially mediated the connection between predictor and criterion due to changes in $\mathrm{R}^{2}$ (from $43 \%$ to $79 \%$ ) and Beta values (-.582 to -.242) while showing the p-values for all the four paths as significant. Therefore, from the results, the second hypothesis is also accepted.

\section{Discussions}

During past decades, the leaders' rewarding and punishing behavior has persistently attracted the attention of the researchers. In an organizational context, it is widely documented that rewards have positive while punishments have negative effects on employees' behavior and considered as significant predictors for effective responsiveness and respectable performances at the workplace (Stajkovic \& Luthans, 2003). The leaders punishing behavior is overseeing negative feedback in the form of criticisms, reprimands, and irritation which the employees receive due to the undesirable behavior and responses (Judge \& Piccolo, 2004). The provision of punishment affects employees' intellectual and psychological abilities accompanied by fairness perceptions (Podsakoff, Bommer, Podsakoff \& Mackenzie, 2006). The fairness in rewards, punishment, and institutional procedures are vital gears in shaping employees' work attitude and organizational citizenship behavior in the institutions (Walumbwa, Wu \& Orwa, 2008). Leadership behavior and justice perception are considered as a potential mechanism for employees' responsiveness, job satisfaction, and performances (Podsakoff, Podsakoff \& Kuskova, 2010). 
The researchers examined the relationships between contingent punishment and employees' work behavior, role ambiguity, and performance along with justice perception with significant outcomes/ results (Michel \& Christian, 2012). When the employees feel discrimination at workplaces then it is expected to harm their emotions, responsiveness, attitudes, and performance (Arman, Latif \& Ali, 2014). The rewards and punishments are used by leaders as the incentive to inspire and encourage the workforces to improve their capabilities and effectively respond to institutional tasks to achieve desired objectives (Zafar, Rehan, Fatima \& Nawab, 2017). The fair behavior of the leadership and management is playing a significant role in shaping the workforces' behavior towards better performances which in turn helps in inducing trust in the leadership in the institutions (Bhatti, Akram, Bhatti \& Bilal, 2019). Consequently, contingent punishment is used as an incentive for inspiring the employees for better performances, however, these encouragements might be more effective when procedural justice (fairness in procedures) is implemented in its true spirit in the institutions.

\section{Conclusion}

The management and leadership, in a higher educational setting, use different approaches to inspire their employees towards the vision and mission of the institutions. In this connection, the rewards and punishments are effective attributes that are used in stirring the employees to respond to institutional objectives more effectively. However, punishments are measured to shape employees' attitudes undesirably. Similarly, fairness in procedures is considered as a stimulating tool in shaping employees' behavior optimistically. Thus, this study confirmed the connection between contingent punishment, procedural justice, and employees' responsiveness. The results revealed the negative association between contingent punishments and employees' responsiveness (-.773 \& .000) with significant impact (-.582 \& .000). However, procedural justice partially mediates the relationship between employees' responsiveness and contingent punishments by bringing change in statistical values (change in $\mathrm{R}^{2}$ values from $44 \%$ to $79 \%$ ) and (change in Beta values from -.582 to -.242). Thus, the study confirmed the mediating role of procedural justice in the relationship between contingent punishments and employees' responsiveness in the context of higher education institutions with certain recommendations.

\section{Recommendations of the Study}

$\checkmark \quad$ The punishment is validated to hurt employees' attitudes and behavior, thus the institutional management is required to avoid the punishment in institutions and use motivation as a tool to inspire employees towards the institutional vision.

$\checkmark \quad$ The institutions might be able to achieve their desired credibility only when employees are responsive towards institutional objectives, thus, management and leadership of institution is required to show all efforts to become the employees more responsive.

$\checkmark \quad$ The fairness in procedures is also a stimulating tool for employees to show their utmost efforts, therefore, the management and leadership are required to show fairness in policies and procedures towards the employees in the institutions.

\section{Contribution of the Study}

$\checkmark \quad$ This study is expected to provide a theoretical contribution to the existing database of knowledge about statistical relationships among research variables under consideration.

$\checkmark \quad$ This study provides an empirical contribution to the impact of contingent rewards on employees' responsiveness in the context of higher education institutions.

$\checkmark \quad$ This study contributes also by providing valuable information about the facilitating role of procedural fairness in connecting the punishments and responsiveness.

$\checkmark \quad$ The realities under study are measured as vital gears for institutional standing and success, thus, the results are expected to provide much information to eye-openers.

\section{Practical Implications}

$\checkmark \quad$ The leaders who use contingent rewards are more expected to inspire their employees instead of those who use contingent punishments as incentives since the rewards shape the behavior positively while punishments shape the behaviors negatively.

$\checkmark \quad$ The employees' perceptions about fairness in procedures while receiving the rewards and punishments are vital in inspiring them to be more responsiveness, thus, fair procedures are vital in shaping the employees' behavior positively in the institutions. 


\section{References}

The assurance of just and fair decisions about the provision of punishments to employees is vital in maintaining their trust in their leadership and management. Thus, continuous monitoring and evaluation of fairness in procedures should be ensured.

Adèr, H. J., Mellenbergh, G. J., \& Hand, D. J. (2008). Advising on research methods: a consultant's companion. Huizen: Johannes van Kessel Publishing. ISBN 978-90-79418-01-5

Arman, H., Latif, L. A., \& Ali, J. (2014). Organizational Justice as a predictor of self-perceived work performance: A perspective from Malaysian higher institution. Mediterranean Journal of Social Sciences, 5 (23), 319-325.

Avolio, B. J., Walumbwa, F. O., \& Weber, T. J. (2009). Leadership: Current theories, research, and future directions. Annual Review of Psychology, 60, 42-49.

Avolio, B. J., Walumbwa, F. O., \& Weber, T. J. (2009). Leadership: Current theories, research, and future directions. Annual Review of Psychology, 60, 42-49.

Bass, B. M., Avolio, B. J., Jung, D. I., \& Berson, Y. (2012). Predicting unit performance by assessing transformational and transactional leadership. Journal of Applied Psychology, 88(2), 207-218.

Benson, T. H., \& Martin, L. (2017). The effect of inter-organizational justice perceptions on organizational citizenship behaviors in construction projects. International Journal of Project Management, 35, 95-106.

Bhatti, H., Akram, U., Bhatti, H., Akram, Z., \& Bilal, M. (2019). Impact of participative leadership on organizational citizenship behavior: Mediating role of trust and moderating role of continuance commitment. Sustainability 11, 1-21.

Chester, A., Tianothy, H., \& Linda, T. (1991). The discriminant validity of the Leader Reward and Punishment Questionnaire and satisfaction with supervision: A two-sample, factor analytic investigation. Journal of Occupational Psychology, 64, 159-166.

Cremer, D., \& Blader, S. L. (2006). Why do people care about procedural fairness? The importance of belongingness in responding and attending to procedures. European Journal of Social Psychology, 36(2), 211-228.

Creswell, John W.(2014). Research design: qualitative, quantitative, and mixed methods approaches (4th ed.). Thousand Oaks: SAGE Publications. ISBN 978-1-4522-2609-5.

Cropanzano, R., Prehar, C. A., \& Chen, P.Y. (2002). Using social exchange theory to distinguish procedural from interactional justice. Group \& organization management, 27 (3), 324-51.

Deng, H., \& Leung, K. (2014). Contingent punishment as a double-edged sword: A dual-pathway model from a sense-making perspective. Personnel Psychology, 67, 951-980.

Diane, E., \& Oliver, D. (2004). Higher Education Challenges in Developing Countries. International Journal of Educational Policy. Research, \& Practice, 5 (2), 3-18.

Dutta, B., \& Islam, M. (2017). Responsiveness of Higher Education to Changing Job Market Demand in Bangladesh. Higher Education for the Future, 4 (1) 60-81.

Elina, M., \& Elita, L. (2017). Idea management and organizational effectiveness: A research gap. Journal of Business Management, 12, 4-23.

Ford, J., \& Stephens, K. (2018). Pairing Organizational and Individual Factors to Improve Employees' Risk Responsiveness. Management Communication Quarterly, 1-30.

Ginkel, H., \& Seddoh, K. (2002). Challenges, perceptions, and priorities: Internationalization of higher education. International Association of University News, 8 (2-3), 1-4.

Greenberg, J. (1990). The organizational justice: Yesterday, today and tomorrow. Journal of Management, 16: 399-432.

Jayachandran, S., \& Varadarajan, R. (2006). Does success diminish competitive responsiveness? Reconciling conflicting perspectives. Journal Academics \& Marketing Science, 34 (3): 284294.

Jayachandran, S., \& Varadarajan, R. (2006). Does success diminish competitive responsiveness? Reconciling conflicting perspectives. Journal Academics \& Marketing Science, 34 (3): 284294.

Judge, T. A., \& Piccolo, R. F. (2004). Transformational \& transactional leadership: a met analytic test of their relative validity. Journal of Applied Psychology, 89 (5), 755-768. 
Judge, T., \& Piccolo, R. (2004). Transformational and transactional leadership: A meta-analytic test of their relative validity. Journal of Applied Psychology, 89, 755-768.

Martin, E., Trigwell, K., Prosser, M., \& Ramsden, P. (2003). Variation in the experience of leadership of teaching in higher education. Studies in Higher Education, 28 (3), 247- 259.

Maryam, M., Suandi, T., Silong, D., \& Omar, Z. (2013). Transformational and transactional leadership styles and job performance of academic leaders. International Education Studies, 6 (11), 29-34.

Matthew, R., \& Stott, C. (2018). The social-psychological processes of 'procedural justice': Concepts, critiques, and opportunities. Criminology \& Criminal Justice, 1-18.

Michel, T., \& Christian, V. (2012). Relationships between leader-contingent and non-contingent reward and punishment behaviors and subordinates' perceptions of justice and satisfaction and evaluation of moderating influence of trust propensity, pay level, and role ambiguity. Journal of Business and Psychology, 28 (2).

Muhammad, S. H., \& Shaheen, M. A. (2015). Impact of organizational justice on job performance in libraries mediating role of leader-member exchange relationship. Library Management, 36 $(1 / 2), 70-85$.

Odumeru, D., James, A., \& Ogbonna, I. (2013). Transformational vs. Transactional Leadership Theories: Evidence in Literature. International Review of Management and Business Research, 2 (2).

Ozsahin, M., \& Yurur, S. (2019). Does organizational justice increase or decrease organizational dissent? Research Journal of Business and Management, V, 6(1), p.1-8

Podsakoff, M., Bommer, H., Podsakoff, P., \& Mackenzie, B. (2006). The relationships between leader reward and punishment behavior and subordinate attitudes, perceptions, and behaviors: A meta-analytic review of existing and new research. Organizational Behavior and Human Decision Processes, 99, 113-142.

Podsakoff, N. P., Podsakoff, P. M., \& Kuskova, V. V. (2010). Dispelling misconceptions and providing guidelines for leader reward and punishment behavior. Business Horizons, 53(3), 291-303.

Raimonda, A., \& Modesta, M. (2016). Leadership style and job satisfaction in higher education institutions. International Journal of Educational Management, 30 (1), 140-164,

Riaz, M. K., \& Farooq, A. J. (2010). The Impacts of Organizational Commitment on Employee Job Performance. European Journal of Social Sciences, 15 (3), 292-298.

Saunders, M., Lewis, P. \& Thornhill, A. (2012). Research methods for business students, 7 ed., England, Pearson education limited.

Sekaran, U. \& Bougie, R. (2011). Research methods for business: A skill-building approach. 5th ed., London, John Wily and Sons Ltd.

Stajkovic, A. D., \& Luthans, F. (2003). Behavioral management and task performance in organizations: Conceptual background, meta-analysis, and test of the alternative models. Personnel Psychology, 56, 155-194.

Uphoff, N., \& Moharir, V. (1994). An analytical model of performance for developing indicators of employees' capability. Journal of Public Administration, 17 (3), 372-379.

Uphoff, N., \& Moharir, V. (1994). An analytical model of performance for developing indicators of employees' capability. Journal of Public Administration, 17 (3), 372-379.

Walumbwa, F. O., Wu, C., \& Orwa, B. (2008). Contingent reward transactional leadership, work attitudes, and organizational citizenship behavior: The role of procedural justice climate perceptions and strength. The Leadership Quarterly, 19, 251-265.

Wang, X., Liao, J., Xia, D., \& Chang, T. (2010). The impact of organizational justice on work performance: Mediating effects of organizational commitment and leader-member exchange. International Journal of Manpower, 31(6), 660-677

Yamane, T. (1967). Statistics: An Introductory Analysis, 2nd Edition, New York: Harper and Row.

Yamane, T. (1967). Statistics: An Introductory Analysis, 2nd Edition, New York: Harper and Row.

Zafar, I., Rehan, M., Fatima, A., Nawab, S. (2017). The impact of organizational justice on employee performance in the public sector organization of Pakistan. International Journal of Economics \& Management Sciences, 6 (3), 1-6. 